\title{
Foliar endophytes in trees varying greatly in age
}

\author{
Zhongdong Yu • Hongru Ding • Kuocheng Shen • \\ Fangfang Bu • George Newcombe $\cdot$ Huixiang Liu
}

Accepted: 28 February 2021 / Published online: 4 March 2021

(C) The Author(s) 2021

\begin{abstract}
Temple trees, including the gymnosperm Platycladus orientalis and the angiosperm Styphnolobium japonicum, have been planted in China for thousands of years. Tree age thus varies widely from young to ancient trees. Foliar endophytes of $P$. orientalis and $S$. japonicum were surveyed in this exploratory study that was based on isolation into culture and sequencing of fungi from trees varying in age from 10 to 5000 years ( $P$. orientalis) and from 10 to 1700 years (S. japonicum). Sequenced endophytes of $P$. orientalis and $S$. japonicum belonged to 24 and 16 fungal genera, respectively. Principal components analysis showed that 14 components were necessary to
\end{abstract}

Z. Yu $(\bowtie) \cdot F . B u$

College of Forestry, Northwest A\&F University,

Yangling 712100, China

e-mail: yuzhongdong001@nwsuaf.edu.cn

H. Ding

College of Life Science, Northwest A\&F University,

Yangling 712100, China

K. Shen

Institute of Botany, The Chinese Academy of Sciences,

Beijing 100093, China

G. Newcombe

College of Natural Resources, University of Idaho, Moscow, ID 83844, USA

e-mail: georgen@uidaho.edu

H. Liu

College of Protection, Shandong Agriculture University,

Tai'an 271018, China explain $90 \%$ of the variance in endophyte community structure in $P$. orientalis. In $S$. japonicum eight components were needed for $90 \%$. It is against that backdrop of complex etiology in community structuring, that the relative frequencies (abundances) of 17 of the 24 endophytes from $P$. orientalis and 9 of the 16 from $S$. japonicum were significantly correlated with tree age. There were two major trends. Abundant fungal genera [Fusarium + Alternaria $=74.57 \%(P$. orientalis $)$ and $81.24 \%$ (S. japonicum)] tended to decline linearly with tree age. Most of the rare fungal genera, in contrast, increased in relative abundance linearly with tree age. Diversity $\left(\mathrm{H}^{\prime}\right)$ and richness (Margalef) of endophyte communities in foliage thus increased as the trees aged. Relative abundances of pathogenic endophytes, or latent pathogens, (Pestalotiopsis funerea and Amyloporia subxantha in P. orientalis; Collectotrichum gloeosporioides and Botryosphaeria dothidea in S. japonicum) also increased linearly as the trees aged.Since leaf age does not vary with tree age in the deciduous $S$. japonicum, nor in the evergreen $P$. orientalis, 'tree age' currently lacks a mechanistic explanation for its apparent importance among common foliar endophytes.

Keywords Platycladus orientalis $\cdot$ Styphnolobium japonicum $\cdot$ Sophora $\cdot$ Mycobiome $\cdot$ Tree age

\section{Introduction}

Long-lived trees are symbols of longevity, as individuals may be hundreds or even thousands of years-old in some 
species. Roots, leaves and seeds harbor largely, tissuespecific communities of fungi (Cregger et al. 2018; Newcombe et al. 2018), Thus, it would seem reasonable to think that the age of those specific tissues also matters. On the other hand, leaf endophytes might not vary with tree age since the age of the leaf tissue varies little, even as trees bearing them get older. Only in Welwitschia mirabilis of the Namib Desert does leaf age match the age of the individual (Chabot and Hicks 1982). This disparity between leaf age and individual age for all other long-lived plants might have implications for trees' foliar mycobiome. These unsettled expectations for 'tree age' as a potentially important factor in foliar endophyte communities point to the need for exploratory research.

For over a millennium Chinese have planted longlived trees in the gardens of temples, on sites of historical and cultural significance, or in their surroundings (Wang et al. 2011). Some old trees draw large crowds of visitors in fall when they are losing their leaves (e.g., a 1400 yearold ginkgo tree next to the Avalokitesvara Temple in the Zhongnan Mountains). Shaanxi Province, in central China, boasts many ancient plantings of long-lived cypress trees (Platycladus orientalis (L.) Franco) and Chinese scholar trees (Styphnolobium japonicum (L.) Schott) in imperial palaces, temples, urban parks, and gardens, along the sides of street, and in tourist destinations. The forest near the Mausoleum of the Yellow Emperor, on the southern margin of the Loess Plateau, is an outstanding example of one such site. The planting of ancient $P$. orientalis in this site constitutes one of the oldest, largest, and best-conserved forests in China. It comprises more than 80,000 trees, of which over 30,000 are more than 1000 years- old. One of these trees, said to have been planted by the Yellow Emperor himself, may be the largest and oldest individual of its species in the world at 5000 years-old (Feng and Han 2009).

Huge, old trees are also home to many different organisms. We focus here on foliar endophytes (Sun et al. 2012; Petrini 1991) that make up the foliar mycobiomes of $P$. orientalis and $S$. japonicum. Both are native to China and their endophyte communities are relatively unstudied. In this paper, we collected leaf samples from old trees of varying age in the Yellow Emperor's Mausoleum as well as two other sites of historical and cultural significance: Yangjian Mausoleum (about 1400 years ago), and Zhougong Temple (about 3200 years ago). The latter two sites are described in more detail below. In this exploratory study we first report on the taxa of fungi found in the mycobiomes of the foliage of these trees. We then report our initial findings on the effects of tree age on endophyte communities in young foliage.

\section{Materials and methods}

Sampling sites for ancient trees

In summer (mid-July) and autumn (early October) of both 2015 and 2016, asymptomatic leaves and branches bearing scale-like leaves, of $S$. japonicum and $P$. orientalis, respectively, were collected at three sites: the Emperor Mausoleum (EM), Zhougong Temple (ZT), and Yangling Mausoleum (YM). EM is at the northern of Guanzhong plain, its mid-temperate, continental monsoon climate (suppl. Fig.1), is characterized by an annual average temperature and precipitation of $9.4{ }^{\circ} \mathrm{C}$ and $\sim 500 \mathrm{~mm}$, respectively (Shaanxi Province Meteorological Bureau 2015, http://www.sxmb.gov. cn/index.php). YM is in the center of the Guanzhong plain (suppl. Fig.1), and the site of the tomb of the emperor Yangjian from the Sui dynasty; it is dotted with mature $S$. japonicum. ZT is in a hilly area to the north of the Qinling Mountains with a warm temperate continental monsoon semi-humid climate with the annual average temperature being $11.9{ }^{\circ} \mathrm{C}$ and annual average precipitation about $631 \mathrm{~mm}$ (Shaanxi Province Meteorological Bureau 2015). There is a clear distinction between the rainy season and the dry season, and floods and droughts alternate from time to time. The minimum precipitation is $18.4 \mathrm{~mm}$ in winter, which accounts for $3 \%$ of annual precipitation, while the maximum precipitation falls in summer and autumn, amounting to $74 \%$ of the annual precipitation (Shaanxi Province Meteorological Bureau 2015). There are two $S$. japonicum trees from the Han Dynasty and two $P$. orientalis trees from the Tang Dynasty in the ZT; these are 1700 and 1200 years old, respectively (Lee 2015). In recent years, populations of long-lived trees in these three sites have declined to varying extent.

We randomly sampled $36 P$. orientalis from different age groups from EM, three $P$. orientalis and five $S$. japonicum from ZT and two $P$. orientalis and six $S$. japonicum from YM. Tree ages were retrieved from official historical documents as per Table 1.All these trees over 100 years old were carefully documented. Ten trees younger than 100 years near the sampling sites were also collected for comparison study, Table 1. Two 


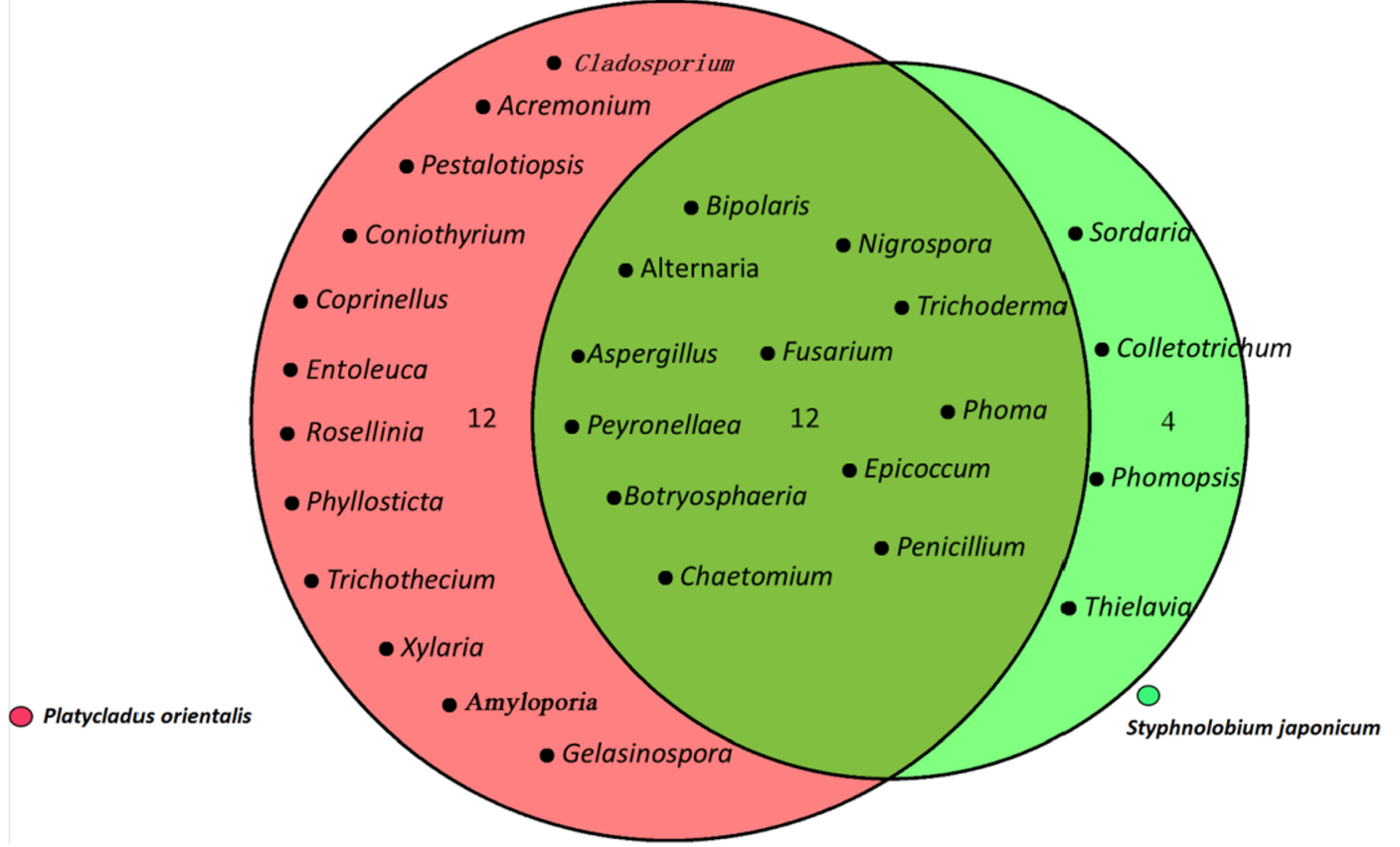

Fig. 1 Fungal endophytic communities in long-lived $P$. orientalis and S.japonicum. Note: The red refers to host-specific endopytes in $P$. orientalis, and the green refers to host-specific endophytes in

branches with leaves from the middle canopy of each tree were taken randomly in each cardinal direction and kept in sealed bags. They returned to the laboratory in an icebox and the isolation work was done within three days according to the protocol (Yu et al. 2016).

Isolation and culture

Basal healthy lateral branches of $P$. orientalis and leaflets from $S$. japonicum were rinsed with tap water and then
S. japonicum. The intermediate refers to the common endophytes of the two tree species

dried on sterile filter paper at $23-25^{\circ} \mathrm{C}$. Lateral branches of $P$. orientalis were surface-sterilized in $10 \%$ sodium hypochlorite liquid for two minutes, while leaflets of S. japonicum were sterilized for two minutes in $2 \%$ sodium hypochlorite. They were then rinsed with sterilized water twice for one minute during each wash. The surface sterilized leaves were selected randomly and then placed on a petri dish of PDA medium at $25^{\circ} \mathrm{C}$ in a dark room. One lateral branch of $P$. orientalis of three $\mathrm{cm}$ long was placed in each dish, while dishes of S. japonicum

Table 1 Ages and numbers of sample trees, and climate factors of three sites, EM, ZT and YM in Shaanxi Province in China

\begin{tabular}{|c|c|c|c|c|c|c|}
\hline & \multicolumn{2}{|l|}{ EM } & \multicolumn{2}{|l|}{ ZT } & \multicolumn{2}{|l|}{ YM } \\
\hline GPS coordinates & \multicolumn{2}{|c|}{ E109.27632/N35.591335 } & \multicolumn{2}{|c|}{ E107.612412/N34.501559 } & \multicolumn{2}{|c|}{ E108.032929/N34.292887 } \\
\hline Temperature $\left({ }^{\circ} \mathrm{C}\right)$ & \multicolumn{2}{|l|}{9.4} & \multicolumn{2}{|l|}{11.9} & \multicolumn{2}{|l|}{10} \\
\hline Precipitation(mm) & \multicolumn{2}{|l|}{500} & \multicolumn{2}{|l|}{630} & \multicolumn{2}{|l|}{600} \\
\hline Species & S. japonica & P. orientalis & S. japonica & P. orientalis & S. japonica & P. orientalis \\
\hline $3-100$ year & 0 & 6 & 1 & 1 & 1 & 1 \\
\hline $100-800$ year & 0 & 6 & 1 & 0 & 4 & 1 \\
\hline $800-1000$ year & 0 & 6 & 1 & 0 & 1 & 0 \\
\hline 1000-2000 year & 0 & 6 & 2 & 2 & 0 & 0 \\
\hline 2000-3000 year & 0 & 6 & 0 & 0 & 0 & 0 \\
\hline $3000-5000$ year & 0 & 5 & 0 & 0 & 0 & 0 \\
\hline 5000- year & 0 & 1 & 0 & 0 & 0 & 0 \\
\hline
\end{tabular}


contained two pieces of intact leaflets without petioles each. Each tree had three replicate petri-dishes per compass point, and thus a total of 12 . Surface sterilization of samples was confirmed by imprinting leaves on PDA medium and incubating dishes at $25^{\circ} \mathrm{C}$ in a dark room for seven days (Yu et al. 2016).

Identification and statistics of endophytic fungi

When colonies developed, pure cultures were isolated by selecting individual colonies. Endophytic fungi were identified at the species level using morphological characterization combined with the ITS-nrDNA blast in GenBank (https://www.ncbi.nlm.nih.gov/genbank), and DNA extraction and sequencing were according to $\mathrm{Yu}$ et al. (2016), clean sequences were deposited in GenBank under accession numbers (KT192185192264; KT192281; KT192329-192422; KR822122822155). After species identification evaluated by both morphological and molecular methods, endophytic communities at genus level were then evaluated by the following indices, Table 2 .

These indices were used to compare the structure of endophytic communities by species, site, and age group. IR refers to the endophyte number per leaf, RF descripts the relatively abundance of a given taxon in a given trial, $\mathrm{H}^{\prime}$, the diversity of an endophyte community in a given trial, $\mathrm{dMa}$, the richness of endophytes in a given trial, and Sorensen index, the endophyte similarity between two given trials.

Data processing and analysis

We used principal component analysis (PCA) to explore the structure of endophyte and samples communities. Firstly, correspondence analyses were carried out at a single tree level, for the composition of endophytic fungal genera isolated from tree-age only, sampling site only, sampling time only, tree-age and sampling time, tree-age and sampling site, and with RF of a given endophytic genus as the response variable, in order to assess the influence of factors, including tree age, sampling time, sampling site, on RF of endophytes. Secondly, canonical correspondence analysis was carried out at the level of fungal genera, to study the influence of the main explanatory variables, including RF, tree-age, sampling time, sampling site, on the occurrence of fungi. Thirdly, the two principal components with the highest variance explained were selected to be plotted by ggplot 2 and PCAtools R.packages. We also used ANOVA and Duncan's new multiple range tests in software SPSS (SPSS 20.0, Chicago, IL, USA) to compare average values of isolate rate, diversity metrics, and similarity coefficients by each category (species, site, and age group). Pearson's correlation coefficient was calculated to establish the degree of correlation between

Table 2 Biodiversity indices

\begin{tabular}{|c|c|c|}
\hline Biodiversity index (Abbreviation) & Formula & References \\
\hline the isolation rate (IR) & $\begin{array}{l}\mathrm{IR}=\mathrm{Nc} / \mathrm{N}_{\mathrm{s}} \\
\mathrm{Nc} \text {, total number of isolates yielded in a given trial } \\
\text { (therein, tree species, tree age, sampling site, } \\
\text { sampling time); Ns, total number of samples } \\
\text { in that trial; }\end{array}$ & Sun et al. 2012 \\
\hline relative frequency $(\mathrm{RF})$ & $\begin{array}{l}\mathrm{RF}=\mathrm{Ni} / \mathrm{N} \\
\mathrm{Ni} \text {, total number of a given taxa (genera) yielded in } \\
\text { a given trial; } \mathrm{N} \text {, total number of isolates yielded } \\
\text { in that trial; }\end{array}$ & Sun et al. 2012 \\
\hline Shannon-Wiener index $\left(\mathrm{H}^{\prime}\right)$ & $\begin{array}{l}H^{\prime}=-\sum_{i=1}^{S}\left(P_{i}\right)\left(\ln P_{i}\right) \\
\mathrm{S} \text { is the number of total taxa (genera), } \mathrm{Pi}=\mathrm{RF}=\mathrm{Ni} / \mathrm{N}\end{array}$ & $\begin{array}{l}\text { Chao et al. } 2005 \\
\text { Yuan et al. } 2010\end{array}$ \\
\hline Richness index (Margalef or dMa) & $\begin{array}{l}(\mathrm{dMa})=(\mathrm{S}-1) / \mathrm{Ln}(\mathrm{N}) \\
\mathrm{S} \text { is the number of taxa (genera), } \mathrm{N} \text { is the total number } \\
\text { of endophytic individuals in a given trial }\end{array}$ & $\begin{array}{l}\text { Sun et al. } 2012 \\
\text { Yuan et al. } 2010\end{array}$ \\
\hline Sorensen similarity coefficient (Sorensen) & $\begin{array}{l}\text { Sorensen }=2 j /(a+b) \\
j \text { is the number of common taxa (genera), a and } b \text { are } \\
\text { the total individual numbers in a given trial, respectively. }\end{array}$ & Cha 1984 \\
\hline
\end{tabular}


RFs of abundant endophytes and their host tree ages. Heatmaps were constructed by pheatmap R.packages. Venn diagrams of the genera of endophytic fungi between the two trees were drawn by ggvenn R.packages. All R.packages are executed in the R software environment (https://www.r-project.org/).

\section{Results and analysis}

Endophytic fungi in long-lived trees

We identified a total of 705 isolates that belonged to 36 species of 28 genera (Suppl. Table 1). Of these, 24 genera represented by 336 isolates $(47.66 \%$ of the total) were from $P$. orientalis and 16 genera represented by 369 isolates were from $S$. japonicum; the two host species shared 12 genera in common (Fig. 1).

Factors in the structure of the foliar microbiomes

Eight components were necessary to explain $90 \%$ of the variance in endophyte community structure of the foliar mycobiome of $S$. japonicum. The two highest principle components (PCs) explained only $58.4 \%$ of the total variance. Tree age influenced the PCA scores (Fig. 2a). Sampling sites were also influential as endophytes from YM were mostly grouped together, as a red circle in Fig. 2a. PCA loadings (Fig. 2b), showed Community A included the two most common genera (i.e.,
Alternaria and Fusarium) and the two genera, Colletotrichum and Botryosphaeria, that have been documented as pathogens (Wilson and Carroll 1994; Slippers and Wingfield 2007). Community B comprised moderately uncommon endophytes, including Cladosporium cladosporioides, Epicoccum nigrum, Peyronellaea glomerata, Trichoderma harzianum, Penicillium glabrum, Penicillium crustosum, Phoma medicaginis and Phoma medicaginis. In addition, Bipolaris sorokiniana was only found in 20-year-old trees (suppl. Tab.1). Community $\mathrm{C}$ consisted of fungi with the lowest RFs: Chaetomium globosum, Nigrospora oryzae, Aspergillus niger, Mucor sp., and Phomopsis sp.

As in $S$. japonicum, tree age of $P$. orientalis influenced endophytic communities. Trees in three age cohorts were recognized: from age 200r to 2500 , young trees and those over-2500. However, the sampling sites and sampling times did not influence endophytic communities as they had in S. japonicum, (Fig. 3a). A full 14 components were necessary to explain $90 \%$ of the variance in endophyte community structure of the foliar mycobiome of $P$. orientalis. The two strongest PCs explained only $33.8 \%$ of the variance.

In the PCA loading plot for P. orientalis (Fig. 3b), Community A again included the two most frequent or abundant genera: Fusarium and Alternaria, and Rosellinia, Amyloporia, Phyllosticta, Pestalotiopsis, Phoma, and Bipolaris. Community B with middle abundance included Xylaria, Chaetomium, Trchoderma,

\section{A: S. japonicum - PCA Score}

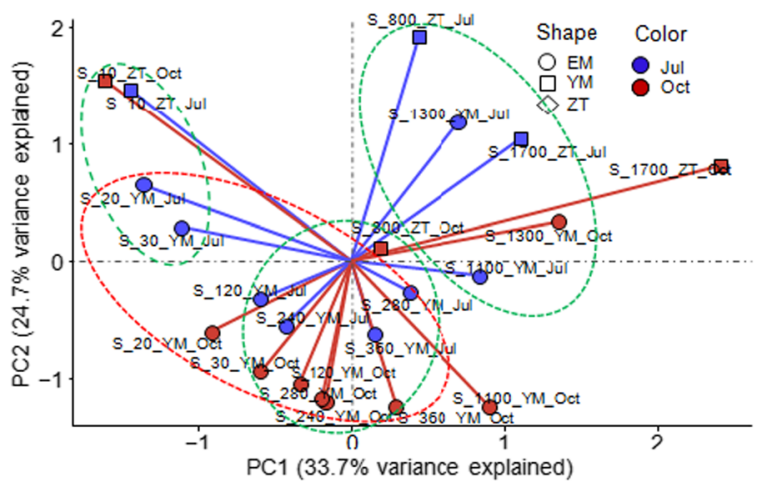

Fig. 2 PCA plot of the foliar endophytes of $S$. japonicum (16 genera, $16 \times 5$ variants; $58.4 \%$ of the total variance). Note: In plota, the sampling trees were labeled as S-old-site-time, respectively; blue dots represent July samplings, and red dots represent Oct. samplings; Shapes of circle, square, diamond represent sampling sites, respectively; The big green circles demonstrate 3 age-groups,

\section{B: S. japonicum - PCA loading}

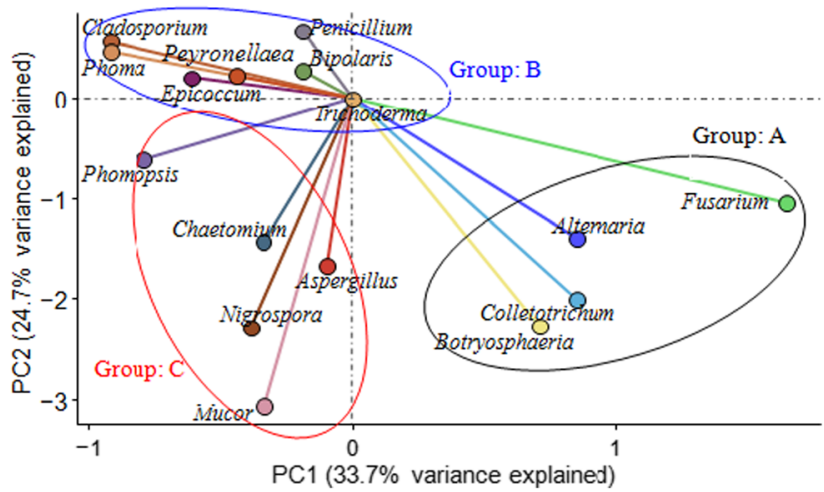

and red circle demonstrates site-group. In plot-b, each dot represents a genera taxon, and the blue, red, black circle demonstrate 3 endophytic communities, respectively. Community A are most pathogens with highest RF data, Community B\&C are most nonpathogenic fungi with low to middle RF data in this survey 
A: P. orientalis - PCA Score

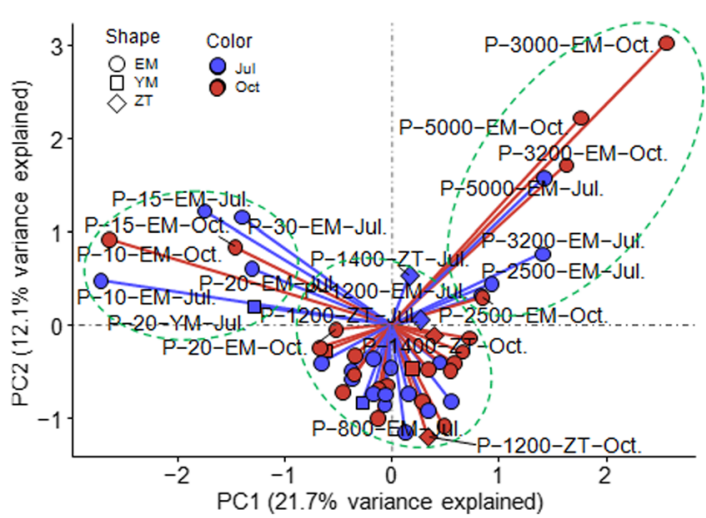

Fig. 3 PCA plot of foliar fungi in $P$. orientalis (24 isolates, $24 \times 5$ variants; $67.2 \%$ of the total variance). Note: In plot-a, the sampling trees were labeled as P-old-site-time, respectively; blue dots represent July samplings, and red dots represent Oct. samplings; Shapes of circle, square, diamond represent sampling sites, respectively; The big green circles demonstrate 3 age-groups. In plot-b,

Epicoccum, Penicillium, Trichothecium and Peyronellaea. Community $\mathrm{C}$ comprised mostly taxa with the lowest RFs, including Cladosporium, Nigrospora, Aspergillus, Acremonium, Conithyrium, Entoleuca, Gelasinospora, and Coprinellus.

Endophytic specificity for host species at different sites

Similarity coefficients of the endophyte community in P. orientalis and S. japonicum in YM, ZT, and EM ranged from 0.31 to 0.45 . All values were less than 0.5 (Table 3 ), which implies significant host-reliance according to an Ftest $(p=0.05)$. And similarity in 1200-year-old $P$. orientalis between ZT and EM was only 0.46 .

Nevertheless, 12 genera of fungi were found in both $S$. japonicum and $P$. orientalis and these were the dominant endophytes in both trees. However, the relative frequencies of these dominant endophytes were quite different. The average relative frequency (RF) of
B: $P$. orientalis - PCA loading

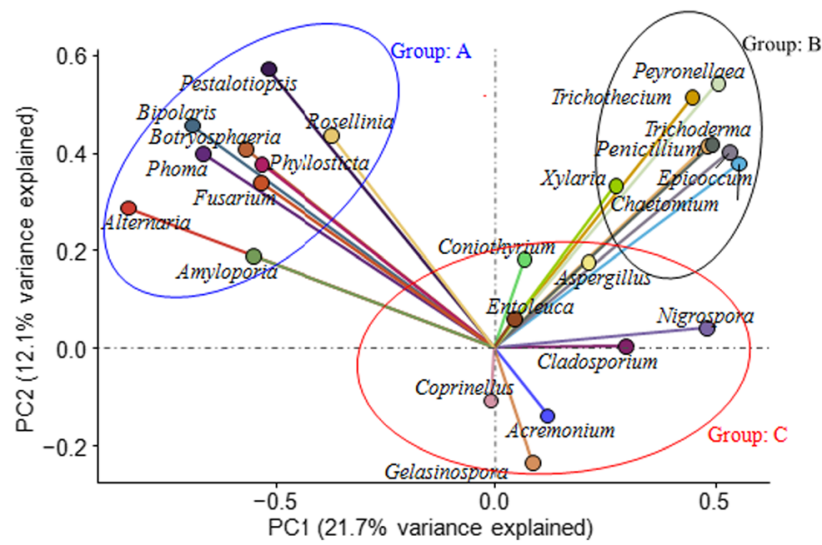

each dot represents a genera taxon, and the blue, red, black circle demonstrate 3 endophytic communities, respectively. Community A are most pathogens with highest RF data, Community $\mathrm{B} \& \mathrm{C}$ are most non-pathogenic fungi with low to middle RF data in this survey

Alternaria in $P$. orientalis $(\mathrm{RF}=33.63 \%)$ was higher than that of $S$. japonicum $(\mathrm{RF}=20.60 \%)$. Conversely the average relative frequency of Fusarium endophytes in leaves of $P$. orientalis $(\mathrm{RF}=10.12 \%)$ was lower than that of $S$. japonicum $(\mathrm{RF}=28.18 \%)$. It is interesting that both $S$. japonicum and $P$. orientalis harbored their own dominant endophytes: Colletotrichum $(\mathrm{RF}=14.09 \%)$ and Xylaria ( $\mathrm{RF}=5.95 \%$ ), respectively. $\mathrm{RF}$ of the dominant endophyte communities showed a significant difference by site at alpha 0.05 levels (suppl. Fig. 2).

Some endophytic communities tended to be hostspecific even in the same environments. Fungal genera in S. japonicum displaying host-specificity included Colletotrichum, Phomopsis, Thielavia, and Sordaria, and in $P$. orientalis they included Acremonium, Coniothyrium, Coprinellus, Trichothecium, Xylaria, Pestalotiopsis, and Gelasinospora (Fig. 1).

In general, the averages of Shannon-Wiener index $(\mathrm{H}$ $'=1.67)$ and the richness index (Margalef $=2.07)$ of

Table 3 Similarity coefficients (Sorensen index) of endophyte communities between long-lived P. orientalis and S. japonicum at different sites (significance $\alpha=0.05$ )

\begin{tabular}{lllll}
\hline Sites & YM $($ S.japonicum $)$ & ZT $($ S.japonicum $)$ & ZT $(P$. orientalis $)$ & EM $($ P.orientalis $)$ \\
\hline YM $($ S. japonicum $)$ & 1.00 & & & \\
ZT $(S$. japonicum $)$ & 0.45 & 1.00 & 1.00 & $0.44 *$ \\
ZT $(P$. orientalis $)$ & $0.37 *$ & $0.44 *$ & 1.00 \\
EM $(P$. orientalis $)$ & $0.31 *$ & $0.42 *$ & & \\
\hline
\end{tabular}


Table 4 Index of endophytic fungi in long-lived Styphnolobium japonicum at different locations (IR, isolation rate; $\mathrm{H}^{\prime}$, diversity index; dMa, richness index)

\begin{tabular}{|c|c|c|c|c|c|c|c|c|c|c|}
\hline & \multicolumn{2}{|c|}{$\begin{array}{l}\text { YM } \\
\text { (S. japonicum) }\end{array}$} & \multicolumn{2}{|c|}{$\begin{array}{l}\mathrm{ZT} \\
(\text { S. japonicum })\end{array}$} & \multirow{2}{*}{$\begin{array}{l}\text { S. japonicum } \\
\text { Average }\end{array}$} & \multicolumn{2}{|c|}{$\begin{array}{l}\mathrm{EM} \\
(P . \text { orientalis })\end{array}$} & \multicolumn{2}{|c|}{$\begin{array}{l}\mathrm{ZT} \\
(P . \text { orientalis })\end{array}$} & \multirow{2}{*}{$\begin{array}{l}\text { P. orientalis } \\
\text { Average }\end{array}$} \\
\hline & Jul. & Oct. & Jul. & Oct. & & Jul. & Oct. & Jul. & Oct. & \\
\hline IR & 7.75 & 4.06 & 5.28 & 3.42 & 5.123 & 5.28 & 3.42 & 3.75 & 2.00 & 3.61 \\
\hline $\mathrm{H}^{\prime}$ & 1.87 & 1.63 & 1.68 & 1.52 & 1.67 & 1.68 & 1.52 & 2.08 & 1.83 & 1.78 \\
\hline $\mathrm{dMa}$ & 1.75 & 1.68 & 2.57 & 2.31 & 2.07 & 2.57 & 2.31 & 3.24 & 2.49 & 2.65 \\
\hline
\end{tabular}

$S$. japonicum were lower than those of $P$. orientalis $(\mathrm{H}$ $'=1.78$, Margalef $=2.65)$, respectively $($ Tab. 4$)$. The diversity, isolate rate and richness of the endophytic communities in the same tree species were higher in summer (July) than in autumn (October), (Table 4), but the relative frequency of a certain isolate in summer was mostly lower than in autumn.

Correlation between endophytic community and tree age

The results show the trend that when the host trees were older, the endophytic communities were more diverse. The indices for diversity and richness of the endophytic communities in 1700-year-old $S$. japonicum were higher than those of endophytic communities in younger trees. The same was true of $P$. orientalis as it grew older; however, no

Table 5 Diversity index of endophyte in long-lived trees at different ages (superscript a, b, c indicate a difference; IR, isolation rate; H', diversity index; dMa, richness index)

\begin{tabular}{lllll}
\hline Species & Tree age & IR & $\mathrm{H}^{\prime}$ & $\mathrm{dMa}$ \\
\hline S. japonicum & $1700 \mathrm{a}$ & $7.25^{\mathrm{ab}}$ & $2.12^{\mathrm{ab}}$ & $2.23^{\mathrm{ab}}$ \\
& $800 \mathrm{a}$ & $4.21^{\mathrm{b}}$ & $1.61^{\mathrm{bc}}$ & $2.04^{\mathrm{bc}}$ \\
& $200 \mathrm{a}$ & $3.42^{\mathrm{b}}$ & $1.50^{\mathrm{b}}$ & $2.07^{\mathrm{bc}}$ \\
& $20 \mathrm{a}$ & $3.41^{\mathrm{b}}$ & $1.42^{\mathrm{c}}$ & $1.96^{\mathrm{c}}$ \\
& $10 \mathrm{a}$ & $3.23^{\mathrm{b}}$ & $1.38^{\mathrm{c}}$ & $1.91^{\mathrm{c}}$ \\
P. orientalis & $5000 \mathrm{a}$ & $7.48^{\mathrm{ab}}$ & $2.15^{\mathrm{ab}}$ & $2.83^{\mathrm{ab}}$ \\
& $3000 \mathrm{a}$ & $7.25^{\mathrm{ab}}$ & $2.25^{\mathrm{ab}}$ & $2.82^{\mathrm{ab}}$ \\
& $2000 \mathrm{a}$ & $6.85^{\mathrm{ab}}$ & $1.99^{\mathrm{ab}}$ & $2.98^{\mathrm{ab}}$ \\
& $1000 \mathrm{a}$ & $5.47^{\mathrm{bc}}$ & $1.77^{\mathrm{bc}}$ & $2.47^{\mathrm{bc}}$ \\
& $800 \mathrm{a}$ & $5.41^{\mathrm{b}}$ & $1.75^{\mathrm{b}}$ & $2.39^{\mathrm{c}}$ \\
& $100 \mathrm{a}$ & $4.52^{\mathrm{c}}$ & $1.63^{\mathrm{c}}$ & $2.23^{\mathrm{c}}$ \\
& $60 \mathrm{a}$ & $3.41^{\mathrm{c}}$ & $1.50^{\mathrm{c}}$ & $2.11^{\mathrm{c}}$ \\
& $10 \mathrm{a}$ & $3.23^{\mathrm{c}}$ & $1.42^{\mathrm{c}}$ & $2.09^{\mathrm{c}}$ \\
\hline
\end{tabular}

difference in diversity and richness was observed when $P$. orientalis trees were over 2000 years-old, (Table 5).

RF of mostly abundance endopytes (9 in S. japonicum and 17 in $P$. orientalis) showed a significantly linear correlation with their hosted tree-age, and some documented pathogens isolated from asymptomatic leaves, for example, Colletotrichum gloeosporioides and Botryosphaeria dothidea in S. japonicum (Fig. 4a), Pestalotiopsis funereal and Amyloporia subxantha in $P$. orientalis (Fig. $4 \mathrm{~b}$ ), their RFs increased linearly with the tree ages, and so did some non-pathogenic endophytes, such as Chaetomium globosum, Cladosporium cladosporioides, Penicillium glabrum, Trichoderma harzianum. However, some endopytes RF decreased linearly with their host ages, such as the most abundant, Alternaria, Fusarium,Phoma,ect. Figure 4.

\section{Discussion}

Tree age was correlated with changes in relative frequency of most of the fungal genera in the endophyte communities of leaves of two, long-lived tree species in central China. However, deciduous trees of vastly different ages all bear current-season leaves only; evergreens maintain leaves that vary in age but all are still much more youthful than old trees that bear them. So, the first question is whether 'tree age' caused those changes in relative frequency? Or, was tree age merely correlated with another factor that caused the observed changes? The most likely 'other factor' would be interaction history of the endophyte communities themselves. Interactions among endophytes can be strong and even exclusive (Raghavendra et al. 2013; Newcombe et al. 2018). In the earlier study, particular endophytes consistently excluded other co-inoculants from developing seed of Centaurea stoebe. Fungi 
Fig. 4 Core members of foliar mycobiomes of $S$. japonicum (a) and $P$. orientalis $(\mathbf{b})$ and their relative frequencies that vary with tree age. Note: Colors from purple to red represents increasing tendency of RF, and the specific $\mathrm{RF}$ data from 0 to 40 is also noted in each square; The table plots above the heatmap displayed the correspondent results of Pearson Correction tests, coefficients marked * or ** manifested the significance for each test

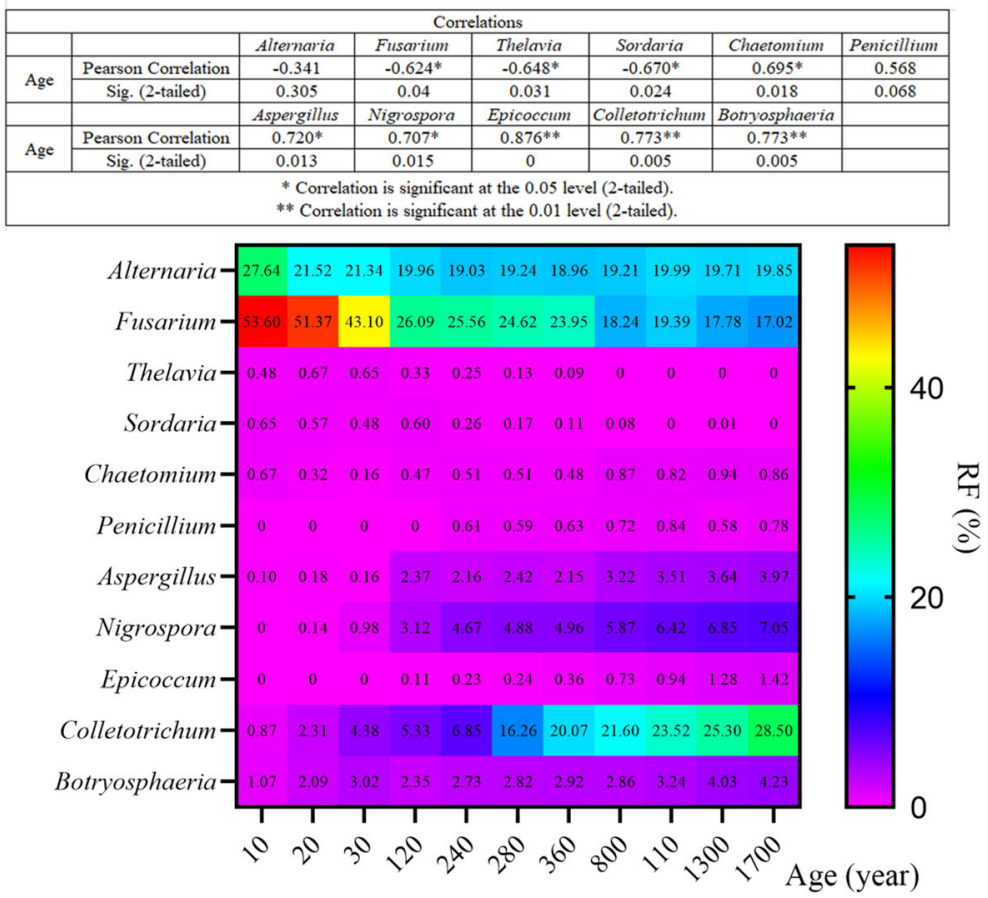

A. Styphnolobium japonicum

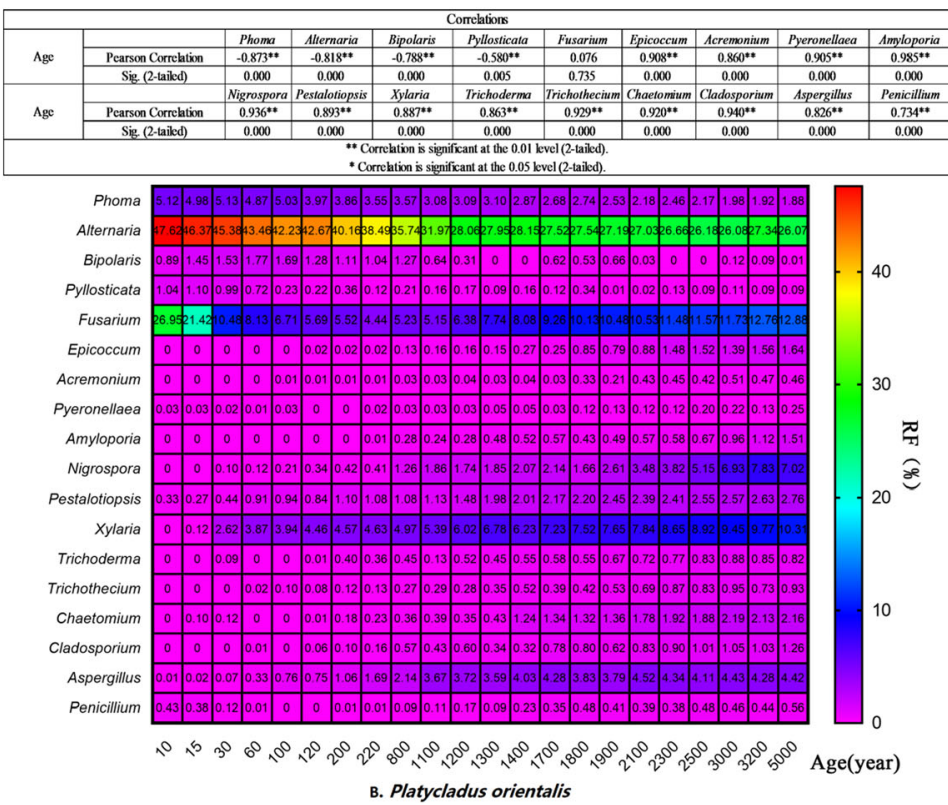

belonging to Pleosporales (e.g., Alternaria) and Hypocreales (e.g., Fusarium) were particularly strong excluders. In this study, it was interesting that those two genera were abundant, especially in the youngest trees.

In trees, newly flushed leaves have been considered to be endophyte-free but then soon colonized by fungal spores of Class 3 endophytic fungi (Faeth and Hammon 1997; Wilson and Carroll 1994; Rodriguez et al. 2009). Spores are dispersed via air, raindrops, and animal vectors from the previous season are senescent and abscised leaves. Germinating spores infect the plant through cuticular invasion, or stomata or wounds (Juniper 1991). 
On the other hand, perennating buds in Pinus can be infected with fungal endophytes (Pirttilä et al. 2003), and it is possible that winter buds of $S$. japonicum and $P$. orientalis might similarly carry over members of the previous year's endophytes. Interestingly, we found that many isolates of endophytic fungi were the same as the documented pathogens in $P$. orientalis and $S$. japonicum in the fields (Farr and Rossman 2021). We picked endophytic $B$. dothidea, and $C$. gloeosporioides in $S$. japonicum, and $A$. subxantha and $P$. funerea in $P$. orientalis for further pathogenicity test. All showed moderate to strong pathogenicity (Suppl. Figs. 3, 4 and 5). Field severity scores for these diseases showed their disease indices (DI) were linearly corrected with these endophytic RFs (Suppl. Fig.6\&7).

Globally, fungal abundances and diversity appear to increase with more precipitation (Ahlholm et al. 2002a, 2002b; Helander et al. 1993, 1994; Yu et al. 2016) and become greater in summer than in late autumn in semiarid regions. Infection frequency may be higher in dense stands (Helander et al. 1993). P. orientalis stands were very dense in the Emperor Mausoleum and sparsely distributed in Zhougong Temple, and isolation rate (IR) of the endophytes in the former was much higher than in the latter. Longer-lived $P$. orientalis over 2300 years are sparsely distributed in their sites, and their endophytic PCA loading plots were more scattered, which indicated difference with age. Habitat fragmentation also likely affected the abundance and diversity of endophytes (Fahrig 2003; Nguyen et al. 2016a, b). Because the Emperor Mausoleum and Zhougong Temple are both tourist spots and frequently disturbed by visitors, endophyte spore transmission, infection, and accumulation might have been affected by management and other human activities.

\section{Conclusion}

Our findings suggest that tree age is an important, structuring factor for foliar endophyte communities but it requires further research, as tree and leaf age do not vary together. Our findings also demonstrate the value of Chinese temple trees for further research to determine the basis for effects of tree age on foliar endophyte communities.

Supplementary Information The online version contains supplementary material available at https://doi.org/10.1007/s10658021-02250-7.
Acknowledgments We thank Miss Qianwen Chen for her help collecting and isolating.

Author contributions YZ, BF conceived and planned the study.BF performed the field investigation and characterization experiments, and $\mathrm{DH}, \mathrm{SC}, \mathrm{BF}, \mathrm{LH}$ analyzed the data. YZ \& GN contributed key ideas, analyzed the data, and wrote the manuscript.

Funding This research was funded by "the national key research projects, grant number 2017YFD0600103-4-2" and National natural science committee, grant number "31670650".

Declarations No potential conflicts of interest existed, and this study did not involve human participants or animals. All of the authors agreed to this publication.

Open Access This article is licensed under a Creative Commons Attribution 4.0 International License, which permits use, sharing, adaptation, distribution and reproduction in anymediumor format, as long as you give appropriate credit to the original author(s) and the source, provide a link to the Creative Commons licence, and indicate if changes were made. The images or other third party material in this article are included in the article's Creative Commons licence, unless indicated otherwise in a credit line to the material. If material is not included in the article's Creative Commons licence and your intended use is not permitted by statutory regulation or exceeds the permitted use, you will need to obtain permission directly from the copyright holder. To view a copy of this licence, visit http://creativecommons.org/licenses/by/4.0/.

\section{References}

Ahlholm, J., Helander, M., Elamo, P., Saloniemi, I., Neuvonen, S., Hanhimäki, S., \& Saikkonen, K. (2002a). Micro-fungi and invertebrate herbivores on birch trees: Fungal mediated plantherbivore interactions or responses to host quality? Ecology Letters, 5, 648-655.

Ahlholm, J. U., Helander, M., Henriksson, J., Metzler, M., \& Saikkonen, K. (2002b). Environmental conditions and host genotype direct genetic diversity of Venturia ditricha, a fungal endophyte of birch trees. Evolution, 56, 1566-1573.

Cha, A. (1984). Non-paramentric estimation of the number of classes in a population. Scandinavian Journal of Statistics, 11, 265-270.

Chabot, B. F., \& Hicks, D. J. (1982). The ecology of leaf life spans. Annual Review of Ecology and Systematics, 13(1), 229-259.

Chao, A., Chazdon, R. L., Colwell, R. K., \& Shen, T. J. (2005). A new statistical approach for assessing similarity of species composition with incidence and abundance data. Ecollgy Letter, 8, 148-159.

Cregger, M. A., Veach, A. M., Yang, Z. K., Crouch, M. J., Vilgalys, R., Tuskan, G. A., \& Schadt, C. W. (2018). The 
Populus holobiont: Dissecting the effects of plant niches and genotype on the microbiome. Microbiome, 6(31), 1-14.

Faeth, S. H., \& Hammon, K. E. (1997). Fungal endophytes in oak trees: Long term patterns of abundance and associations with leaf miners. Ecology, 78, 810-819.

Fahrig, L. (2003). Effects of habitat fragmentation on biodiversity. Annual Review of Ecology and Systematics, 34, 487-515.

Farr, D. F., \& Rossman, A. Y. (2021). Fungal Databases. ARS, USDA: U.S. National Fungus Collections Retrieved February 9, 2021, from https://nt.ars-grin. gov/fungaldatabases/.

Feng, B., \& Han, Y. B. (2009). Possible effect of solar activity on variation of the tree-rings of a 500 a Platycladus orientalis at the mausoleum of emperor Huang. Science in China Series G-Physics Mechanics \& Astronomy, 4, 631-639.

Helander, M. L., Neuvonen, S., Sieber, T., \& Petrini, O. (1993). Simulated acid rain affects birch leaf endophyte populations. Microbial Ecology, 26, 227-234.

Helander, M. L., Sieber, T. N., Petrini, O., \& Neuvonen, S. (1994). Endophytic fungi in scots pine needles: Spatial variation and consequences of simulated acid rain. Canadian Journal of Botany-Revue Canadienne de Botanique, 72, 1108-1113.

Juniper, B. E. (1991). The leaf from the inside and the outside: A microbe's perspective. Microbial Ecology of Leaves. Springer New York, 21-42.

Lee, M. H. (2015). Study on Oracle bone script 'Ningfeng' of Western Zhou. The Society for Chinese Cultural Studies, 29, 157-174 (in Korean).

Newcombe, G., Harding, A., Ridout, M., \& Busby, P. E. (2018). A hypothetical bottleneck in the plant microbiome. Frontiers in Microbiology, 9, 1645. https://doi.org/10.3389 /fmicb.2018.01645.

Nguyen, D., Boberg, J., Cleary, M., Bruelheide, H., Hönig, L., Koricheva, J., \& Stenlid, J. (2016a). Foliar fungi of Betula pendula: Impact of tree species mixtures and assessment methods. Scientific Reports, 7, 41801.

Nguyen, D., Boberg, J., Ihrmark, K., Stenstrom, E., \& Stenlid, J. (2016b). Do foliar fungal communities of Norway spruce shift along a tree species diversity gradient in mature European forests? Fungal Ecology, 23, 97-108.
Petrini, O. (1991). Endophytes of tree leaves. In J. H. Andrews, \& S. S. Hirano (Eds.), Microbial ecology of leaves (pp. 179196). London:Brock/springer series in contemporary bioscience.

Pirttilä, A. M., Pospiech, H., Laukkanen, H., Myllylä, R., \& Hohtola, A. (2003). Two endophytic fungi in different tissues of scots pine buds (Pinus sylvestris L.). Microbial Ecology, 45(1), 53-62.

Raghavendra, A. K. H., Newcombe, G., Shipunov, A., Baynes, M., \& Tank, D. (2013). Exclusionary interactions among diverse fungi infecting developing seeds of Centaurea stoebe. FEMS Microbiology Ecology, 84(1), 143-153.

Rodriguez, R. J., White, J. F., Arnold, A. E., \& Redman, R. S. (2009). Fungal endophytes:Diversity and functional roles. The New Phytologist, 182, 314-330.

Slippers, B., \& Wingfield, M. J. (2007). Botryosphaeriaceae as endophytes and latent pathogens of woody plants: Diversity, ecology and impact. Fungi Biological Reviews, 21(2-3), 90106.

Sun, Y., Wang, Q., Lu, X. D., Okane, I., \& Kakishima, M. (2012). Endophytic fungal community in stems and leaves of plants from desert areas in China. Mycological Progress, 11, 781790.

Wang, Z., Fang, J., Tang, Z., \& Lin, X. (2011). Patterns, determinants and models of woody plant diversity in China. Proceedings of the Royal Society: Biological Sciences, 278(1715), 2122-2132.

Wilson, D., \& Carroll, G. C. (1994). Infection studies of Discula quercina, and endophyte of Quercus garryana. Mycologia, 86, 635-647.

Yu, Z. D., Tang, G. H., \& Cao, Z. M. (2016). Diversity and community structure of endophytic fungi in the leaves of Populus simonii in Shaanxi province. Sciential Silvae Sinicae, 6, 86-92 (in Chinese).

Yuan, Z. L., Zhang, C. L., Lin, F. C., \& Kubicek, C. P. (2010). Identity, diversity, and molecular phylogeny of the endophytic mycobiota in the roots of rare wild rice (Oryza granulate) from a nature reserve in Yunnan, China. Applied and Environmental Microbiology, 76(5), 1642-1652. 